\title{
FROM COCOA TO CHOCOLATE
}

Authors: Dijana Miličević, Sanja Oručević Žuljević and Zahida Ademović

Reviewers: Đurđica Ačkar, Biljana Pajin

THE CONTENT OF THE BOOK: The book has 290 pages, and the content is divided into 10 chapters. In the introductory chapters written something about the origin of cocoa beans, its basic characteristics, and the impact on human health. In subsequent following chapters describes the technological process of production of chocolate harvesting, fermentation and drying of cocoa beans, through its preparations in terms in the sense of burning and shredding, the production of cocoa powder and chocolate mass from it, and chocolate and chocolate products. In the book are described rheological properties as a very important factor in the quality of chocolate products, and finally an overview of some types of chocolate, as well as the basic quality properties of chocolate. The book has a large number of pictures, diagrams and tables which are complemented content of book. The book will be published on the website and will be accessible to anyone who is interested in its subject matter. 